\title{
Mass Vaccination and Surveillance/Containment in the Eradication of Smallpox
}

\author{
J. M. Lane ( \\ 869 Clifton Road NE, Atlanta, GA 30307-1223, USA \\ mikelane869@yahoo.com
}

1 Background

2 Initial Plans for Mass Vaccination Against Measles and Smallpox

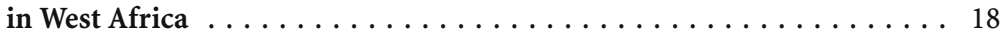

3 Contrasting Epidemiology of Measles and Smallpox in West Africa . . . . 19

4 Observations Leading to Increased Importance

of Surveillance and Outbreak Containment $\ldots \ldots \ldots \ldots \ldots$

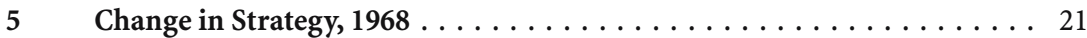

6 Elements of the Surveillance/Outbreak Containment Strategy . . . . . . 22

$7 \quad$ Results in West Africa . . . . . . . . . . . . . . . . . . 23

$8 \quad$ Results in Asia . . . . . . . . . . . . . . . . . . . . . 24

9 Validation by Mathematical Modeling $\ldots \ldots \ldots \ldots \ldots$

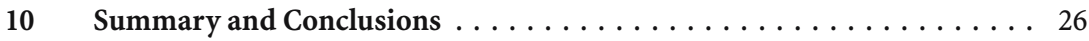

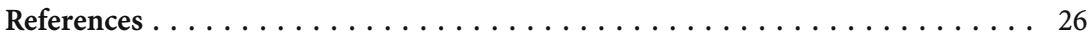

Abstract The Smallpox Eradication Program, initiated by the WHO in 1966, was originally based on mass vaccination. The program emphasized surveillance from the beginning, largely to track the success of the program and further our understanding of the epidemiology of the disease. Early observations in West Africa, bolstered by later data from Indonesia and the Asian subcontinent, showed that smallpox did not spread rapidly, and outbreaks could be quickly controlled by isolation of patients and vaccination of their contacts. Contacts were usually easy to find because transmission of smallpox usually required prolonged face-to-face contact. The emphasis therefore shifted to active searches to find cases, coupled with contact tracing, rigorous isolation of patients, and vaccination and surveillance of contacts to contain outbreaks. This shift away from mass vaccination resulted in an acceleration of the program's success. 


\section{Background}

During 1967-1969, the World Health Organization's Smallpox Eradication Program shifted emphasis from mass vaccination to surveillance and containment. The shift evolved from early field experiences by the Center of Disease Control (CDC) staff who improvised new approaches based on their developing understanding of the epidemiology of smallpox, and the relative ease of its control. This chapter summarizes these data and experiences, and comments on the results of the initial efforts in surveillance and containment.

In 1964 the World Health Organization (WHO) Expert Committee on Smallpox mandated $100 \%$ vaccination coverage to eradicate smallpox, rather than an $80 \%$ level of herd immunity as previously claimed (WHO 1964). These experts assumed that smallpox was highly contagious and would therefore find isolated pockets of susceptible population. The committee emphasized the need to measure levels of immunity by developing methods of rapid and reliable assessment of vaccination coverage. Around the same time, jet injector technology was being developed for rapid point-of-collection immunization (Millar et al. 1969; Roberto et al. 1969; Neff et al. 1969). Coincidentally, trials in the early 1960s, which showed the safety and efficacy of measles vaccine in Africa, led many West African public health advocates to request assistance with measles control. (Meyer et al. 1964) These developments set the stage for the West African measles/smallpox campaign.

2

\section{Initial Plans for Mass Vaccination Against Measles and Smallpox in West Africa}

The initial plan for the smallpox eradication/measles control program was to do mass vaccination of the entire population for smallpox, and all children under the age of 5 years for measles. The program used mobile teams going village to village, with collection point vaccination. Measles had a high case fatality rate in sub-Saharan Africa, about 5\%. (Morley 1967) There was therefore considerable interest in the successful trial of measles vaccine in Upper Volta (now Burkina Faso). This led USAID to advocate a measles vaccination campaign through West Africa (Meyer et al. 1964). CDC agreed to provide technical assistance to this campaign if smallpox eradication was added to the effort (Fenner et al. 1988). Simultaneous childhood measles and universal smallpox vaccination was started in 1967, using collection-point 
mass vaccination with jet injector guns as the main strategy. Collection point mass vaccination utilized the jet guns maximally, and helped the logistics of handling measles vaccine, which required careful refrigeration. The jet guns were cumbersome and made house-to-house visitation awkward. Collection point mass immunization and treatment methods had been successfully used throughout much of West Africa to control yellow fever and yaws, so that public health authorities were comfortable with mass vaccination concepts (Hopkins 1985; Tomori 2002).

CDC and WHO were vitally interested in adding disease surveillance to the effort, mostly as a method of assessing the results of the smallpox and measles immunization program. Surveillance and outbreak investigations also allowed direct comparison of the epidemiology of measles and smallpox in similar communities. While superficially similar, the epidemiology of measles and smallpox in West Africa proved to be quite different.

\section{3}

\section{Contrasting Epidemiology of Measles and Smallpox in West Africa}

Measles in West Africa was highly infectious and had about a $5 \%$ case fatality rate (Morley 1967). The median age of attack was less than 2 years. Virtually all children got the disease. Transmission was common in gathering places such as markets, schools, or other gathering places. It was difficult to trace chains of transmission. In large urban areas such as the city of Dakar, measles would exhaust all susceptibles and require continual re-introductions from outside the city to maintain transmission (Rey et al.1968). One case often caused six or more new cases. Once the disease was introduced into a household or compound, the attack rate among exposed susceptibles was usually nearly $100 \%$.

Smallpox was much less infectious. The median age of attack was in the mid-teens or early 20s (Foege et al. 1975). Chains of transmission were easy to trace. Most transmission was to intimate household contacts (Henderson and Yekpe 1969). One case rarely spread the disease to as many as three others. Very small tribal groups, as few as 200 or so, often sustained transmission for six or more generations (Imperato et al. 1973). In individual compounds with extended family groups, the interval between the onset of the first case and the onset of the last case was frequently 6 weeks, and often was 8 weeks (Foege et al. 1975). The two viral exanthems, although superficially similar, behaved very differently in the community. 


\section{4 \\ Observations Leading to Increased Importance of Surveillance and Outbreak Containment}

Four observations led the CDC to give increased emphasis on surveillance of smallpox and rapid containment of outbreaks. First, in early 1967 Dr William H. Foege, who had agreed to head the smallpox and measles efforts in the Eastern State of Nigeria, detected a substantial epidemic of smallpox in several communities in Ogoja Province. The initial shipments of vaccine had not arrived. He called upon a network of friends and medical missionaries in the area, and suggested that they use their very limited supplies of vaccine to vaccinate close contacts of cases and possibly attenuate the outbreak. To his delight the outbreak was rapidly eliminated (Foege et al. 1975). In retrospect Dr C.W. Dixon had observed similar results in Tripolitania shortly after World War II. He rapidly eliminated a substantial outbreak among the Arab population with very limited supplies of glycerinated lymph vaccine. He vaccinated occupants of tents in which cases were found, telling his workers to vaccinate residents of surrounding tents only if there was sufficient vaccine. Dixon coined the term 'ring vaccination', which has become synonymous with the vaccination strategy of surveillance/containment (Dixon 1948).

Second, shortly after the Ogoja Province outbreak showed that smallpox was relatively easy to eliminate with vaccination of small numbers of close contacts, Dr Foege and his colleagues conducted a textbook mass vaccination campaign in the Eastern Nigerian city of Abakaliki. Independent field assessment with a carefully drawn sample of the city showed that $88 \%$ of the population had been effectively vaccinated, with the major cutaneous reactions that WHO used as criteria for 'take'. Shortly thereafter there was an outbreak of 33 cases of smallpox in the city (Thompson and Foege 1968). This observation cast doubt on the ability of mass vaccination alone to eliminate the disease.

Third, while these observations were being made in West Africa, data from several studies of the epidemiology and viral shedding of Asian Variola major became available. These studies showed that the vast majority of spread was to persons with very close prolonged face-to-face contact with obviously sick patients. Most transmission occurred during the first 5 or 6 days of the rash when the patient was prostrate and visibly ill. Secondary household attack rates among susceptibles were as low as $36 \%$ in the seasonal downswing of the disease, and the highest recorded was only $88 \%$ during the seasonal increase. Rarely did any patient spread smallpox to more than three other patients, perhaps in part because they were too sick to be effectively mobile (Rao et al. 1968; Mack et al. 1972; Sommer and Foster 1974; Heiner et al. 1971; 
Thomas et al. 1971). Joint US, UK, and Indian researchers used plates of viral culture medium placed near patients in a smallpox hospital to show that viral shedding was detected only within 6 feet of the patient. Virus was not shed during the first 2 or 3 days of the prodrome when the patients were very ill, but had not yet developed an enanthem in the back of the nose and throat (Downie et al. 1965).

Finally, review of the epidemiology of imported smallpox in Europe from 1950 to 1971 yielded similar data on the relatively slow spread of the disease. There were very few large outbreaks. Indeed 13 of 47 importations resulted in no spread at all. The average number of cases per importation was just 15. Over $50 \%$ of cases acquired smallpox in hospital, when undiagnosed very sick patients were not fully isolated (Mack 1972). In commenting on this study the author wrote "It is my judgment that under contemporary conditions smallpox cannot be said to live up to its reputation. Far from being a quick-footed menace, it has appeared as a plodding nuisance with more bark than bite." Mack has subsequently pointed out that smallpox probably would have been eliminated in developed nations, even without vaccine, by prompt isolation of patients (Mack 2003).

\section{5}

\section{Change in Strategy, 1968}

During the fall of 1968, the CDC program in West Africa, led by Dr Foege, changed its strategy for smallpox eradication. Foege and his colleagues reasoned that the relatively slow spread of smallpox, with the ease of aborting outbreaks by vaccination of contacts, made the disease susceptible to control by actively searching for cases and concentrating on vaccinating their household and village contacts. Foege was also impressed by the marked seasonality of the disease. He believed that if outbreaks could be found during the West African seasonal low in September through January, and chains of transmission broken by patient isolation and/or vaccination of close contacts, a large decrease in the seasonal high from February through June would result from a fairly small effort. In India less than $1 \%$ of villages were infected at any one time, suggesting that only modest numbers of vaccinations were necessary if reporting could be improved (National Institute of Communicable Diseases of India 1968). CDC thus laid plans for intensive active surveillance in the fall of 1968 and early winter of 1969 (Foege et al. 1971). 
6

\section{Elements of the Surveillance/Outbreak Containment Strategy}

The surveillance and outbreak control strategy is conceptually simple, but required several changes in emphasis from the straightforward mass vaccination technique. Improvements in surveillance were central to the effort. Passive reporting through the medical care system was very poor in the newly emerging nations of West Africa. Reporting efficiency in Nigeria was only about $5 \%$ of actual cases, and was poor in other areas of West Africa (Henderson et al. 1973). Instead of relying on formal medical reports, CDC teams went to markets and schools, and showed pictures of typical cases of smallpox, inquiring whether anyone had seen similar patients in their village in recent weeks. They quickly learned that tribal and civil authorities knew more about the health conditions in the villages than the medical hierarchy. Surveillance became an active search, rather than passive reliance on traditional disease notification by medical personnel.

A second element is improved isolation of patients. Patient isolation can be very effective in controlling smallpox since patients are not infectious during the first 3 days or so of the prodrome, and transmission is usually only to contacts with prolonged direct face-to-face exposure. Indeed one experienced observer suggests that in developed countries smallpox could be eradicated by isolation alone (Mack 2003). Many tribes in West Africa hid cases because they had learned that isolation in smallpox hospitals was tantamount to a death sentence. Medical and nursing care was poor in most African smallpox hospitals, and patients were not given good food and fluids. Family members could do a better job of nursing patients, and particularly feeding them, given that there was no actual therapy for smallpox. A system of home isolation with careful education of family members and villagers, coupled with vaccination of caregivers, replaced forced hospitalization.

A third element is identification of contacts. This proved easy once contacts realized that being vaccinated might save them from developing smallpox. Many of the CDC operations officers in the program had been sexually transmitted disease investigators in the US, and were experienced in interviewing and contact tracing.

A fourth element is vaccinating the contacts. The biology and immunology of smallpox allows contacts to be spared the disease if they are vaccinated within about 3 days after contact (Massoudi et al. 2003; Kennedy et al. 2004). CDC staff quickly realized that vaccinating contacts with the jet injector guns was cumbersome and time consuming, whereas all workers in the program could carry several vials of vaccine and containers of sterile bifurcated needles. They could vaccinate contacts wherever and whenever they were found. Fully 
$100 \%$ of contacts had to be vaccinated, which meant that teams often made multiple visits to infected villages, including staying at night to vaccinate villagers who had gone to markets or were engaged in remote agricultural activities.

A fifth element of the new strategy is placing contacts under careful and close surveillance, so that they can be isolated as soon as they develop early prodromal symptoms of smallpox (smallpox is not infectious until 3 or 4 days after the beginning of the febrile prodrome). Surveillance could be accomplished by program team members, local health workers, or village officials trained to do the task.

The final element of the surveillance/containment strategy is vaccinating the 'second ring', i.e., the contacts of contacts. In practice this often meant vaccinating an entire village once the initial contacts had been carefully identified and vaccinated. The second ring was vaccinated in case there was a vaccine failure in one of the first ring contacts, or a failure to identify a contact already infected.

\section{7}

\section{Results in West Africa}

The shift from mass vaccination to surveillance and outbreak containment rapidly accelerated smallpox eradication. Figure 1 shows the secular trend of smallpox in the 19 nations of West and Central Africa, displayed on a semi-log scale as the ratio of observed cases to those expected from the mean of the 7 years from 1960 to 1967 . This corrects for the sharp seasonal trend observed in the historical data. When active search began in the fall of 1968, there was an immediate increase in cases detected. This was followed by a rapid decline, with smallpox being finally eradicated more than 18 months in advance of the original target date (Foege et al. 1971; Foege 1996)

In late 1967, during the tensions leading to, and then the actual conduct of, the Biafra Civil War, the Eastern State of Nigeria shifted from mass vaccination to surveillance and containment and interrupted transmission in just 5 months, with only 750000 of the state's 12 million population vaccinated (Foege et al. 1975). Sierra Leone had the highest incidence of reported smallpox in all of Africa in 1967, and started its mass vaccination program a year later than most of the other West African nations. It eradicated smallpox rapidly, and indeed three of its four largest outbreaks, and seven of its 13 administrative districts, cleared smallpox completely before the planned beginning of mass vaccinations (Hopkins et al. 1971). Mali eradicated smallpox with barely $51 \%$ of its population vaccinated (Foege et al. 1975). There were similar success stories in Guinea, Togo, Upper Volta, and Northern Nigeria. 


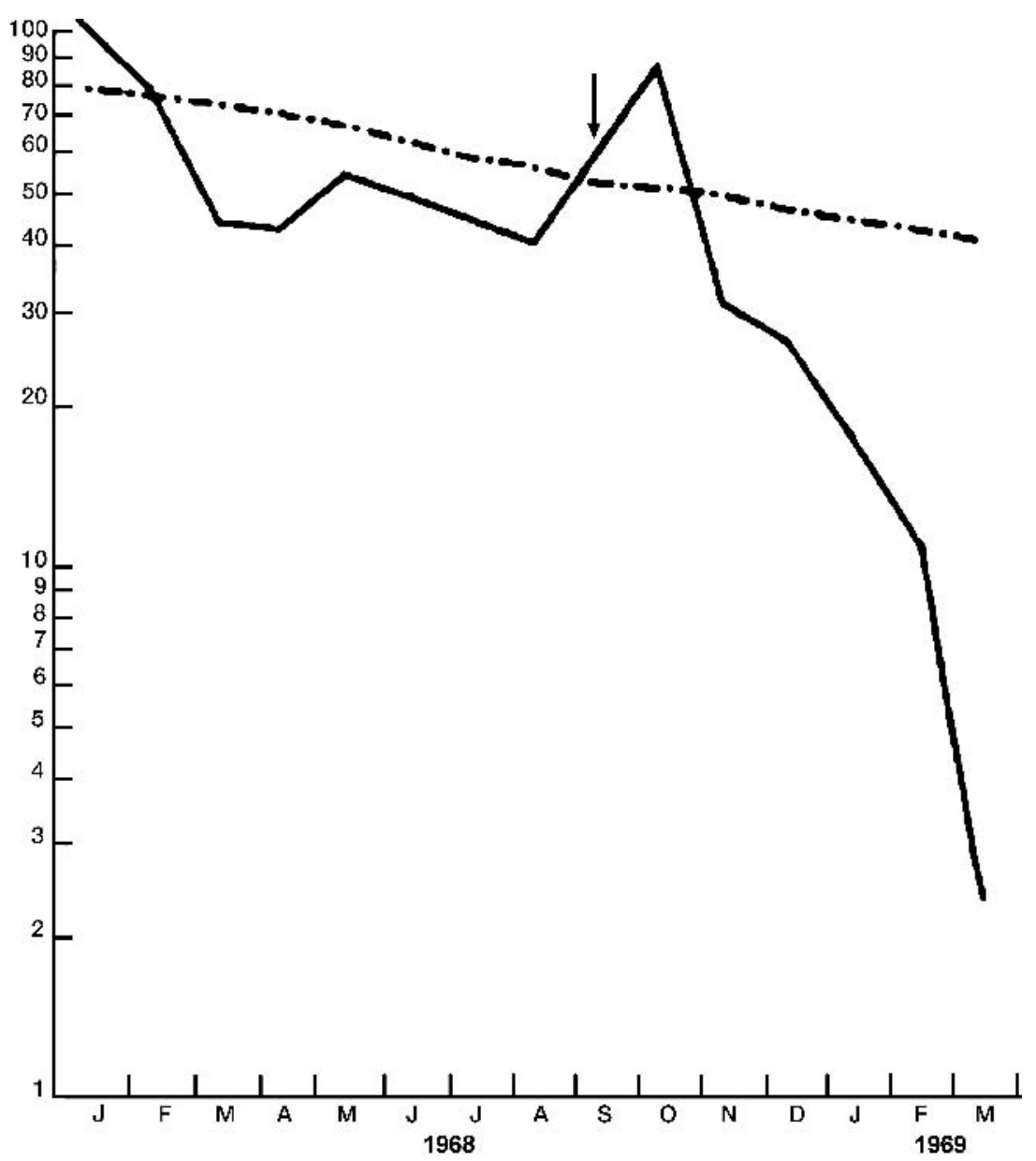

Fig. 1 The percentage of the population not vaccinated in the smallpox eradication program areas of West and Central Africa (broken line) compared with the ratio (\%) of reported smallpox cases to cases expected from the 1960-67 monthly average (solid line). The arrow marks the start of surveillance-containment activities

\section{8}

\section{Results in Asia}

The results of the emphasis on surveillance and outbreak control in West Africa were sufficiently impressive so that WHO urged other nations, particularly in Asia, to adopt the strategy as a mainstay of their eradication programs. The success of these measures is well documented in the defini- 
tive history of the WHO Smallpox Eradication Programme (Fenner et al. 1988). In the Indonesian province of West Java, a fortuitous experiment took place in which Bogor regency did surveillance/containment alone, Bandung regency did surveillance/containment combined with mass vaccination efforts aimed at reducing the backlog of unvaccinated population, and Tjirebon regency first did mass vaccination to reduce the backlog, followed by surveillance/containment. The outcome convinced Indonesian authorities of the superiority of surveillance/containment, and they were instrumental in helping WHO convince Indian program leaders to adopt the strategy.

The Asian efforts included improvements and extensions of the basic steps in the surveillance/outbreak containment methods. In India increasing rewards were made for reporting bona fide cases of smallpox, with increasing values ( 25 to 50 to 100 rupees) as the final cases were found. In Bangladesh family health workers lived for nearly 2 weeks in each infected village to assist with vaccination, and guards were posted at houses where infected patients were isolated. Surveillance built in measures of the time from the onset of each patient's illness to the time of report, the time between initiating control measures and the onset of the last case in the outbreak, and similar methods of documenting the speed of finding cases and contacts. The time taken to control outbreaks became the measure most closely monitored, other than the actual decline of cases itself.

\section{9}

\section{Validation by Mathematical Modeling}

In 2002 concerns about the use of smallpox as a bioterrorist weapon led to planning for handling outbreaks with unnatural sources. Kaplan and his colleagues constructed a mathematical model of smallpox outbreaks, and claimed that surveillance and outbreak containment methods did not work as well as mass vaccination. His model included several aspects that are not consistent with historical experience; only $50 \%$ of contacts were found, patients spread the disease during the asymptomatic period of their infection, and quarantine and isolation of patients and contacts was not fully effective (Kaplan et al. 2002). Several other investigators, using a variety of different mathematical modeling methods but employing realistic biological parameters consistent with historical field experience, have found that surveillance and containment methods works better than mass vaccination in virtually all scenarios (Meltzer et al. 2001: Halloran et al. 2002: Bozette et al. 2003; Eichner 2003; Eubank et al. 2004; LeGrand et al. 2004: Porco et al. 2004; Glasser et al. 2005). 


\section{0}

\section{Summary and Conclusions}

Unique biologic and epidemiologic aspects of smallpox allow it to be rapidly eliminated by surveillance and outbreak containment techniques. Patients have a characteristic visible rash, which is easy for non-medical personnel to recognize. The disease is not infectious in the early stages of the prodrome, while the patients are very sick. This keeps patients from being mobile and spreading the virus. The vast majority of spread is to very close contacts, who are thus easy to identify. Vaccination early in the incubation period is effective in stopping the development of the illness. Emphasis on finding cases, isolating them, and vaccinating their contacts accelerated the eradication of smallpox, and allowed de-emphasis of mass vaccination methods. Surveillance and careful isolation of patients may be important in other diseases spread by large droplet respiratory secretions, such as SARS.

In the author's opinion, a terrorist attack in the US using smallpox should not prompt mass vaccination. Mass vaccination with current first generation vaccinia strains would cause considerable morbidity and mortality (Lane and Goldstein 2003). It would be unnecessary given the efficiency and ease of surveillance and containment in a nation with sophisticated communications systems (Mack 2003; Lane and Goldstein 2003). If widespread simultaneous releases of large volumes of aerosolized smallpox took place in several cities, mass vaccination might become politically inevitable, but during the campaign contacts of known cases would still be ethically and epidemiologically the most important people to receive vaccination. Thus surveillance and containment methods would have to accompany any mass vaccination efforts, and should receive the highest priority. The post $9 / 11$ efforts to create a cadre of vaccinated health care workers in the U.S. was not a mass vaccination effort, but rather an attempt to selectively immunize people known to be at high risk of exposure to smallpox in an attack given the frequency of nosocomial spread.

\section{References}

Bozzette SA, Boer R, Bhatnagar V, Brower JL, Keeler EB, Morton SC, Stoto MA (2003) A model for a smallpox-vaccination policy. N Engl J Med 348:416-425

Dixon CW (1948) Smallpox in Tripolitania, 1946; an epidemiological and clinical study of 500 cases, including trials of penicillin treatment. J Hygiene 46:35-77

Downie AW, Meikeljohn M, St Vincent L, Rao AR, Sundara Babu BV, Kempe CH (1965) The recovery of smallpox virus from patients and their environment in a smallpox hospital. Bull World Health Org 33:615-622 
Eichner M (2003) Case isolation and contact tracing can prevent the spread of smallpox. Am J Epidemiol 158:118-128

Eichner M, Dietz K (2003) Transmission potential of smallpox: estimates based on detailed data from an outbreak. Am J Epidemiol 158:110-117

Eubank S, Guclu H, Kumar VS. Marathe MV, Srinivasan A, Toroczkai Z, Wang N (2004) Modelling disease outbreaks in realistic urban social networks. Nature 429:180-184

Fenner F, Henderson DA, Arita I, Jezek Z, Ladnyi ID (1988) Smallpox and its Eradication. World Health Orgianization, Geneva

Foege WH (1996) Commentary: Smallpox eradication in West and Central Africa revisited. Bull World Health Org 76:233-235

Foege WH, Millar JD, Lane JM (1971) Selective epidemiologic control in smallpox eradication. Am J Epidemiol 94:311-315

Foege WH, Millar JD, Henderson DA (1975) Smallpox eradication in West and Central Africa. Bull World Health Org 52:209-222

Foster SO (1977) Smallpox eradication: lessons learned in Bangladesh. WHO Chronicle $31(6): 245-247$

Gani R, Leach S (2001) Transmission potential of smallpox in contemporary populations. Nature 414:748-751

Glasser J, Foster SO, Millar JD, Lane JM (2005) Evaluating public health responses to reintroduced smallpox via dynamic, socially structured, and spatially distributed meta-population models. Am J Epidemiol (in press)

Halloran ME, Longini IM Jr, Nizam A, Yang Y (2002) Containing bioterrorist smallpox. Science 298:1428-1433

Henderson RH, Yekpe M (1969) Smallpox transmission in southern Dahomey. A study of a village outbreak. Am J Epidemiol 90:423-428

Henderson RH, Davis H, Eddins DL, Foege WH (1973) Assessment of vaccination coverage, vaccination scar rates, and smallpox scarring in five areas of West Africa. Bull World Health Org 48:183-194

Heiner GG, Fatima N, McCrumb FR (1971) A study of intrafamilial transmission of smallpox. Am J Epidemiol 94:316-26

Hopkins DR (1985) Control of yaws and other endemic trepanematoses: implementation of vertical and/or integrated programs. Rev Infect Dis 7S:338-342

Hopkins DR, Lane JM, Cummings EC, Thornton JN, Millar JD (1971) Smallpox in Sierra Leona II: the 1968-69 eradication program. Am J. Trop Med and Hyg 20:697-704

Imperato PJ, Sow O, Benitieni F (1973) The persistence of smallpox in remote unvaccinated villages during eradication programme activities. Acta Tropica 30:261-268

Kaplan EH, Craft DL, Wein LM (2002) Emergency repose to a smallpox attack: The case of mass vaccination. Proc Nat Acad Sci USA 99:10935-10940

Kennedy JS, Frey SE. Yan L, Rothman AL, Cruz J, Newman FK, Orphin L, Belshe RB, Ennis FA (2004) Induction of human T cell-mediated immune responses after primary and secondary smallpox vaccination. J Infect Dis 190:1286-1294

Lane JM, Goldstein J (2003) Evaluation of 21st-century risks of smallpox vaccination and policy options. Annals of Int Med 138:488-493

Legrand J, Vibound C, Boelle PY, Valleron AJ, Flahault A (2004) Modeling responses to a smallpox epidemic taking into account uncertainty. Epidemiol Infect 132:19-25

Mack TM (1972) Smallpox in Europe 1950-1971. J Infect Dis 125:161-169 
Mack TM (2003) A different view of smallpox and vaccinia. New Engl J Med 348:460463

Mack TM, Thomas DB, Ali A, Khan MM (1972) Epidemiology of smallpox in West Pakistan I acquired immunity and the distribution of disease. Am J Epidemiol 95:157-168

Massoudi, MS, Barker L, Schwartz B (2003) Effectiveness of postexposure vaccination for the prevention of smallpox: results of a Delphi analysis. J Infect Dis 188:973-976

Meltzer MI, Damon I, LeDuc JW, Millar JD (2001). Modeling potential responses to smallpox as a bioterrorist weapon. Emerg Infect Dis 7:959-969

Meyer HM, Hostetler DD, Bernheim BC, Rogers NG, Lambin P, Chassary A, Labusquiere R, Smadel JE (1964) Response of Volta children to live attenuated measles vaccine. Bull World Health Org 30:769-781

Millar JD, Foege WH (1969) Status of eradication of smallpox (and control of measles) in West and Central Africa. J Infect Dis 120:725-732

Millar JD, Roberto RR, Wulff H, Wenner HA, Henderson DA (1969) Smallpox vaccination by intradermal jet injection. I Introduction, background, and results of pilot studies. Bull World Health Org 41:749-760

Morley DC, Martin WJ, Allen I (1967) Measles in West Africa.West Afr Medl J Nigerian Pract 16:24-31

Mukherjee MK, Sarkar JK, Mitra AS (1974) Pattern of intrafamilial transmission of smallpox in Calcutta, India. Bull World Health Org 51:219-215

National Institute of Communicable Diseases of India (1968) Evaluation of the National Smallpox Eradication Program in Karnal District, Haryana. New Delhi

Neff JM, Millar JD, Roberto RR, Wulff Hl (1969) Smallpox vaccination by intradermal jet injection. III Evaluation in a well vaccinated population Bull World Health Org 41:771-778

Porco TC, Holbrook KA, Fernyak SE, Portnoy DL, Reiter R, Aragon TJ (2004) Logistics of community smallpox control through contact tracing and ring vaccination: a stochastic network model. BMC Publ Health 4:34

Rao AR, Jacob ES, Kamalakshi S, Appaswamy S, Bradbury (1968) Epidemiological studies of smallpox. A study of intrafamilial transmission in a series of 254 infected families. Ind J Med Res 56:1826-1854

Rey M, Cantrelle P, Lafaix C, Mar ID, Sow A, Agboton Y (1968) Lessons of an experimental campaign of vaccination against measles in the urban environment. (in French) Bulletin de la Societe Medicale d Afrique Noire de Langue Francaise. 13:291-231

Roberto RR, Wulff H, Millar JD (1969) Smallpox vaccination by intradermal jet injection. II Cutaneous and serological responses to primary vaccination in children. Bull World Health Org 41:761-769

Sommer A, Foster SO (1974) The 1972 Smallpox outbreak in Khulna municipality, Bangladesh 1. Methodology and epidemiologic findings. Am J Epidemiol 99:291302

Thomas DB, McCormack WM, Arita I, Khan MM, Islam S, Mack TM (1971) Endemic smallpox in rural East Pakistan. I. Methodology, clinical and epidemiological characteristics of cases and intravillage transmission. Am J Epidemiol 93:361372 
Thompson D, Foege WH (1968) Faith Tabernacle Smallpox Epidemic, Abakaliki, Nigeria. WHO/SE/68.3

Tomori O (2002) Yellow fever in Africa: public health impact and prospects for control in the 21 st century. Biomedica 22:178-210

World Health Organization (1964) WHO expert committee on smallpox First Report Technical Report Series No. 283 